\title{
Phosphonated Polyurethanes that Resist Calcification
}

Ravi R. Joshi, ${ }^{\star}$ Jack R. Frautschi, ${ }^{\dagger}$ Richard E. Phillips, Jr., ${ }^{\dagger}$ and Robert J. Levy*

Departments of Pediatrics, Communicable Diseases, and Pharmaceutics, The University of Michigan, Ann Arbor, Michigan and ${ }^{+}$CarboMedics, $1300-B$, East Anderson Lane, Austin, Texas

\begin{abstract}
Cardiovascular implant mineralization involving bioprosthetic materials, such as glutaraldehyde cross linked porcine aortic valves or synthetic materials such as polyurethanes, is an important problem that frequently leads to clinical failure of bioprosthetic heart valves, and complicates long-term experimental artificial heart device implants. Novel, proprietary, calcification resistant polyetherurethanes (PEU) as an alternative to bioprosthetic materials were the subject of these investigations. A series of PEU was derivatized through a proprietary reaction mechanism to achieve covalent binding of 100 to $500 \mathrm{n} M / \mathrm{mg}$ of bisphosphonate (2-hydroxyethane bisphosphonic acid, HEBP). The stability of HEBP (physically dispersed or covalently bound) verified by studying the release kinetics in physiological buffer ( $\mathrm{pH} \mathrm{7.4)}$ at $37^{\circ} \mathrm{C}$, demonstrated the covalent binding reaction to be stable, efficient, and permanent. Surface (FTIR-ATR, ESCA, SEM/EDX) and bulk (solubility, GPC) properties demonstrated that the covalent binding of HEBP occurs in the soft segment of the PEU, reduces surface degradation, and does not affect the original material properties of the PEU (prior to derivatization). In vitro calcium diffusion of the derivatized $P E U$ showed a decrease in calcium permeation as the concentration of HEBP covalent binding was increased. In vivo properties of underivatized and derivatized PEU (containing $100 \mathrm{n} M$ of covalently bound HEBP) were studied with rat subdermal implants for 60 days. Explants demonstrated calcification resistance due to the covalently bound HEBP without any side effects. It is concluded that a PEU containing HEBP might serve as a calcification resistant candidate material for the fabrication of a heart valve prosthesis and other implantable devices. (C) 1994 John Wiley \& Sons, Inc.
\end{abstract}

\section{INTRODUCTION}

Segmented polyurethane copolymers are well known medical grade elastomers that are frequently used in fabricating various blood contacting devices due to this material's versatile properties such as blood compatibility, hydrolytic stability, superior abrasion resistance, excellent physical strength, and high flexural endurance. ${ }^{1-3}$ These attributes of polyurethane result from the microphase separation of the hard segment and the elastomeric soft segment. ${ }^{1}$ In most of the biomedical polyurethanes, the hard segment is usually composed of methylene diphenyl diisocyante (MDI), 1-4 butanediol, or diamine (chain extender). The soft segment is usually composed of polytetramethylene oxide (PTMO). Depending upon the composition of the above-mentioned reactants, the polyetherurethanes (PEUs) are useful in a variety of applications including fabrication of various types of blood contacting devices such as vascular prostheses, catheters, pacemaker leads, artificial hearts, heart valve

Requests for reprints should be sent to Prof. Robert J. Levy, R-5014, Kresge II, The University of Michigan, Ann Arbor, MI 48109.

Journal of Applied Biomaterials, Vol. 5, 65-77 (1994)

(C) 1994 John Wiley \& Sons, Inc. CCC 1045-4861/94/010065-13 prostheses, and ventricular assist devices. However, the use of this material for long-term applications in cardiovascular implants is often hampered by calcification.

Pathological calcification is defined as the deposition of calcium phosphates (chiefly hydroxyapatite) in ectopic sites, that is, sites other than normal mineralized tissue such as bone or dental mineral. Calcification is also the leading cause of failure of contemporary bioprosthetic heart valves. ${ }^{4}$ In vitro and in vivo calcification of biomedical PEUs has been reported in the literature. ${ }^{5-9} \mathrm{Be}-$ sides this, their stability and biocompatibility in vivo has been questioned. Hence the use of such materials in long-term implants such as cardiac valve prostheses and ventricular assist systems has been restricted.

Prior work from our group ${ }^{10-12}$ and Golomb and Wagner ${ }^{13}$ demonstrated that sustained release of either the $\mathrm{Na}$ or $\mathrm{Ca}$ salt of hydroxyethanebisphosphonate (HEBP) from polymer matrices composed of materials such as ethylene vinyl acetate, polydimethylsiloxane, or polyurethane, prevent calcification with no side effects. This was due to local and low systemic dosage. ${ }^{10-14}$ In another related study from our laboratory, controlled release of the above HEBP salts from refillable PEU reservoirs was also found to inhibit calcification of rat subdermal pericardial bioprosthetic implants. ${ }^{14}$ However, all of these studies were based on the 
regional controlled release of HEBP. Once the agent has been exhausted from the matrices or reservoirs, the implanted material can begin calcifying. Thus, this strategy for preventing calcification is not an ultimate solution to avoid calcification of permanent cardiovascular implant. Therefore, our approach in this study was to characterize a new series of proprietary PEUs that contain covalently immobilized HEBP. No such materials have been previously considered.

In the present studies, HEBP was covalently bound to a de novo synthesized PEU through a proprietary reaction mechanism. The objectives of these investigations were: to assess the stability of the bound HEBP (with comparison to HEBP-disperison); characterize (surface and bulk) the modified polymers; evaluate and compare in vitro calcium transport properties of the modified and control PEUs; and in vivo assessment of inhibition of calcification using a rat subdermal model.

\section{MATERIALS AND METHODS}

\section{Materials}

A de novo proprietary synthesized medical grade polyurethane (PEU) (CarboMedics, Austin, TX) was derivatized by covalently binding 100 to $500 \mathrm{nM} / \mathrm{mg}$ of the anticalcifying agent HEBP. The anticalcifying agent was isolated and purified from Dequest 2010 (Monsanto Co., St. Louis, MO) by concentrating this solution through the evaporation of Dequest 2010 raised to boiling temperature, followed by seeding the saturated solution with acid HEBP crystals. ${ }^{14} \mathrm{C}$ geminal carbon atom labeled disodium 1,1 hydroxyethylidene bisphosphonate $\left(\mathrm{Na}_{2} \mathrm{HEBP}\right.$ ) (specific activity $144 \mu$ curie $/ \mathrm{mL}$ ) was provided by Procter and Gamble, Inc. (Cincinnati, OH). Anhydrous tetrahydrofuran (THF) and other anhydrous solvents used during the experimental work (Aldrich Chemical Co., Milwaukee, WI) were used as received without any further purification. Ecolume counting cocktail (ICN Biomedical Inc., Irvine, CA) was used for all liquid scintillation studies. HEPES ( $N$-[hydroxy ethyl] piperazine- $N$-[ethane sulfonic acid]) and Trizma (tris[hydroxymethyl] amino methane) (Sigma, St. Louis, MO) buffer was used for in vitro release studies. Biomer ${ }^{\circledR}$ (Ethicon, Somerville, NJ), and Mitrathane $^{\circledR}$ (Polymedica, Denver, CO) medical grade PEUs (polyetherurethane urea) supplied $25 \%$ solution in dimethyl acetamide were used as received without any further purification.

\section{HEBP-Binding Stability: In Vitro Release Study}

Typically, five PEU films $\left(1 \mathrm{~cm}^{2}\right)$ containing covalently bound and physically dispersed ${ }^{14} \mathrm{C}$ HEBP were individually incubated at $37{ }^{\circ} \mathrm{C}$ in $5 \mathrm{~mL}$ of physiological buffer (0.05 $M$ HEPES at $\mathrm{pH} 7.4)$ with constant stirring (100 rpm) by using an orbital shaker (Lab Line, Melrose
Park, CA). At specified time intervals over the 365day release period, the releasate was exchanged and analyzed by combining it with $15 \mathrm{~mL}$ of Ecolume and then counted for ${ }^{14} \mathrm{C}$ activity using a Beckman liquid scintillation counter (Model 3801, Berkeley, CA). The release profiles of HEBP from the PEU films were plotted as the cumulative amount of HEBP retained versus time.

\section{In Vitro $\mathrm{Ca}^{2+}$ Diffusion Studies}

The diffusion of the calcium across the underivatized and derivatized (unimplanted) membranes was studied using acrylic two-cell diffusion chambers. After measuring the thickness at five different points $(0.2 \pm 0.0038 \mathrm{~mm}$ thick $)$ the membrane was mounted between the two cells $(n=$ 4). The donor cell contained at $45 \%$ solution of calcium chloride, and the receptor cell contained $0.05 M$ (pH 7.4.) Trizma buffer. The diffusion chambers were placed on an orbital shaker at $120 \mathrm{rpm}$ at $37^{\circ} \mathrm{C}$. At each time point, the receptor cell was totally evacuated, rinsed with deionized double distilled water, and replenished with fresh buffer. Data were plotted as the cumulative calcium diffused $(\mu \mathrm{g})$ as the function of time (days).

\section{In Vivo Studies}

Sample Preparation. The base polymer Mitrathane ${ }^{\circledR}$ dissolved in THF was cast on Teflon (Al plastics, Austin TX) into sheets approximately $0.035-\mathrm{cm}$ thick. After $48 \mathrm{~h}$ drying at $70{ }^{\circ} \mathrm{C}$ under vacuum, the Mitrathane ${ }^{\circledR}$ was cut into $1 \mathrm{~cm}^{2}$ pieces. The test polymers, namely HEBP derivatized (containing $100 \mathrm{nM}$ of covalently bound HEBP), Biomer ${ }^{\circledR}$, and Mitrathane ${ }^{\circledR}$, were individually coated over the Mitrathane ${ }^{\circledR}$ by dipping into a solution of each test polymer to a final thickness of $0.0381 \mathrm{~cm} \pm$ $10 \%$. The coated samples were dried at $125^{\circ} \mathrm{C}$ for $1 \mathrm{~h}$ to remove any residual stress.

Implant Procedure. Male weanling rats $(50-60 \mathrm{~g}$, CD Sprague Dawley, Charles River Laboratories, Burlington, MA) were anesthetized using ketamine (Parke Davis, Morris Plains, NJ; $0.057 \mathrm{mg} / \mathrm{g}$ ) and xylazine (Haver, Shawnee, KA; $0.008 \mathrm{mg} / \mathrm{g}$ ) as described elsewhere. ${ }^{15}$ The test polymer samples were implanted into these anesthetized rats in subcutaneous pouches dissected in the ventral abdominal wall. The implant duration was 60 days. Animals were maintained on Lab Chow Ralston Purina, St. Louis, MO) during the study. The animals were weighed prior to implant and then they were sacrificed. The explanted polymer samples were characterized for surface and bulk properties.

\section{Methods}

Representative explanted samples from each group were prepared for material analyses by washing ( $\mathrm{pH} 1.8$ ) with $0.6 \%$ pepsin to remove surface adsorbed proteins, and 
were then analyzed for surface and bulk properties. The changes in the materials were evaluated by comparison with pepsin-washed unimplanted control samples. Three samples per formulation were analyzed and the mean results were taken into account for interpretation of the data.

Electron Spectroscopy for Chemical Analysis. Electron spectroscopy for chemical analysis (ESCA) were obtained on a Perkin-Elmer 5400 (Eden Prairie, MN). The underivatized, derivatized, and implanted derivatized PEU samples were fixed on the sample holder by doublesided tape, and degassed for $24 \mathrm{~h}$ under high vacuum. A $5 \mathrm{eV}$ electron flood gun was used to offset charge accumulation on the sample. Elemental compositions were determined on the basis of the areas under each electron spectra curve from the corresponding element present in the sample at a pass energy of $150 \mathrm{eV}$. To prevent inelastic scattering, the analyses were performed under vacuum $\left(10^{7}-10^{8}\right.$ torr $)$.

Fourier Transform Infrared Spectroscopy-Attenuated Total Reflectance. Fourier transform infrared spectra of the samples were measured by attenuated total reffectance spectroscopy (FTIR-ATR) using a Nicolet 5DXC spectrophotometer (Nicolet, Model 60SX, Wisconsin, MD). The variable angle ATR attachment was used with a KRS-5 parallelogram crystal $\left(50 * 10 * 3 \mathrm{~m}^{3}\right)$. the films were placed in between the crystal. All spectra were the results of an accumulation of 200 scans collected at a resolution of $2 \mathrm{~cm}^{-1}$ at a $45^{\circ}$ angle of incidence after subtracting from the spectra of the glue. All spectra were recorded under similar identical conditions, and were corrected for atmospheric water vapor and carbon dioxide transmittance by subtraction of the appropriate reference spectrum. The air-cast surfaces of the underivatized and derivatized films were scanned for the analysis.

Scanning Electron Microscopy (SEM) and Energy Dispersive X-Ray Spectroscopy (EDX). The air dried surfaces of each type of specimen $(0.2 \pm 0.0038 \mathrm{~mm}$ thick), were characterized by SEM (Hitachi Model S-570, Santa Clara, CA) and EDX (Kevax-8000, Foster City, CA) after sputtering with graphite under vacuum. A $150 \mathrm{mtorr}$ vacuum with a current density of $20 \mathrm{~mA}$ and $1500 \mathrm{~V}$ was used to develop an $\sim 15$-nm thick layer of graphite coating.

Gel Permeation Chromatography (GPC). GPC of the samples was performed using a Waters liquid chromatography system (Model No. 440, Waters, Milford, MA) attached with a UV detector. The styragel columns (crosslinked styrene-divinyl benzene packing material) with pore size of $10^{2}, 10^{3}$, and $10^{4} \AA$ attached in series were used. The flow rate of the degassed THF mobile phase was $1.0 \mathrm{~mL} / \mathrm{min}$. Monodispersed polystyrene standards dissolved in THF were used to calibrate the system.
Results were expressed as relative molecular weight values.

Water Uptake Studies. The water absorption capacity of the samples were determined by immersing the sample film $\left(1 \mathrm{~cm}^{2}, 0.2 \pm 0.0038 \mathrm{~mm}\right.$ thick $)$ in deionized double distilled water at $37^{\circ} \mathrm{C}$ for $72 \mathrm{~h}$. The absorbed water content of each specimen was evaluated from the weight difference before and after $72 \mathrm{~h}$ immersion.

\section{Quantitative Calcium and Phosphorus Analyses.} Explanted samples and unimplanted samples were quantitatively analyzed for mineralized calcium and phosphorous elements by hydrolyzing samples freeze dried to a constant weight in $6 \mathrm{~N} \mathrm{HCl}$ at $100{ }^{\circ} \mathrm{C}$ for $24 \mathrm{~h}$ to dissolve and elute all the mineralized elements adsorbed or absorbed. The hydrolysate was appropriately diluted for calcium and phosphorus analysis. The total calcium level was determined by using atomic absorption spectroscopy (AAS) (Perkin-Elmer 2380, Norwald, CT). ${ }^{16}$ Phosphorus was quantitatated using an ammonium-molybdate complexation assay. ${ }^{17}$

\section{RESULTS}

\section{Solubility}

Solution containing 40 to $45 \%(\mathrm{w} / \mathrm{v})$ of the above PEUs were prepared in polar solvents such as THF and dimethyl acetamide (DMAc). These PEUs were readily soluble forming translucent solutions. To speed the dissolution at room temperature, the polymer sample mixture on stirring resolved as a single phase and was free of gel particles or cloudiness. However, the relative rate of dissolution differed for all samples. The relative order of solubility observed was derivatized (explanted) $>$ derivatized (control) $>$ nonderivatized. This suggests that some change in the bulk property of the polymer occurred on derivatization and implantation. Explanted Mitrathane ${ }^{\circledR}$ samples, when combined with DMAc solvent, disintegrated forming a turbid solution. This might be due to the degradation of the polymer and extensive mineralization (see following).

\section{HEBP-Binding Stability: In Vitro Release Study}

The comparative release of HEBP covalently bound to PEU versus HEBP physically dispersed in PEU was verified by monitoring the release kinetics of radiolabeled HEBP. Figure 1 illustrates the release profile for derivatized polyurethane containing $45.5 \pm 2.3,86.2 \pm 1.1$, and $398.7 \pm 2.2 \mathrm{n} M$ of HEBP covalently bound, and $458.17 \pm 1.3 \mathrm{nM}$ of HEBP physically dispersed in the polymer. HEBP covalently bonded to PEU when monitored for 365 days demonstrated that more than $75 \%$ of 


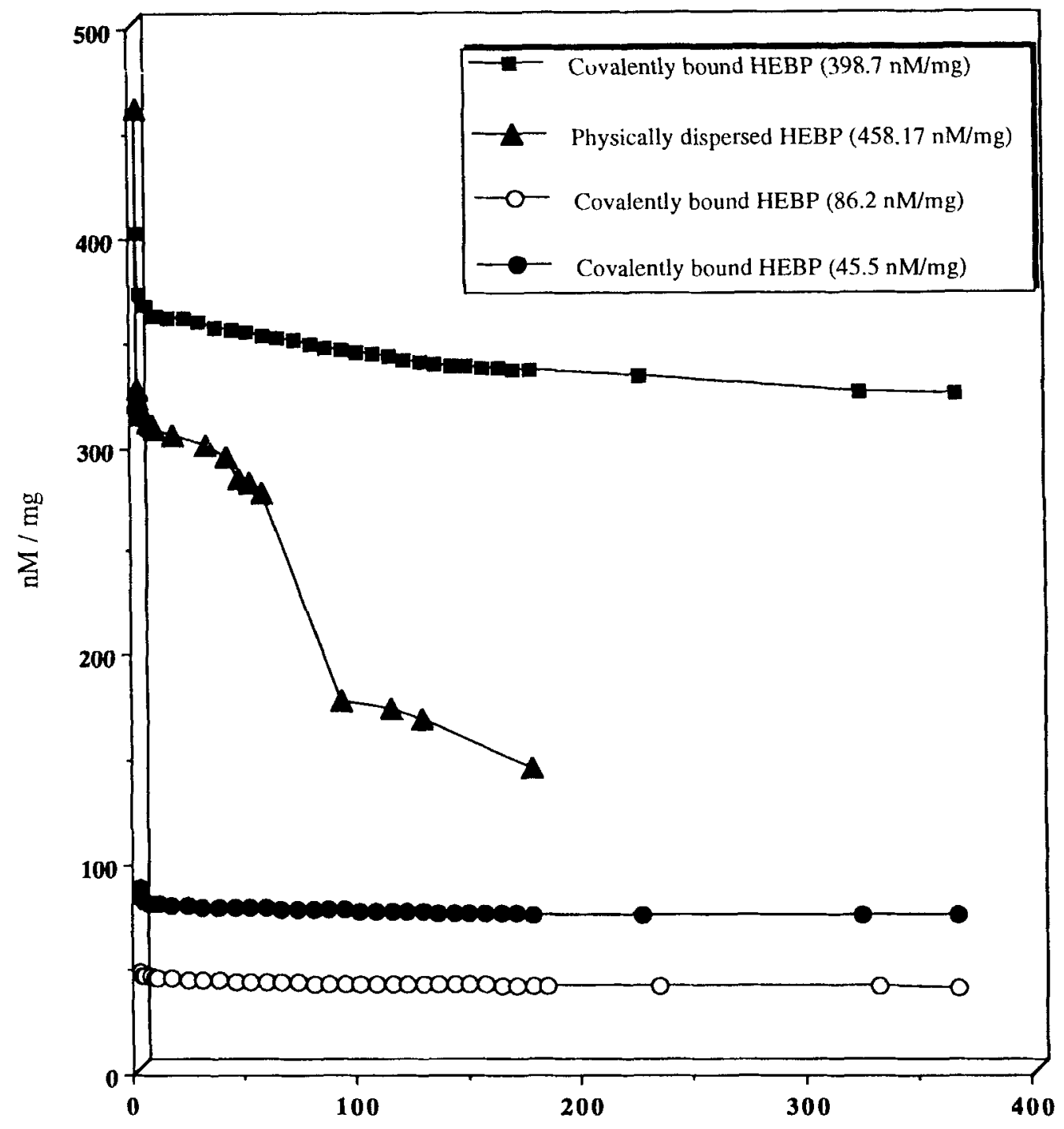

Time (Days)

Figure 1. Release profile (residual) of covalently bound compared to physically dispersed HEBP (nM/mg) from polyurethane (PEU) films.

the total anticalcifying agent originally incorporated in the polymer was still present. The initial $25 \%$ of nonbound HEBP released from derivatized samples during the first 2 weeks might be due to the diffusion of the unreacted HEBP, or due to the dissociation of low molecular weight HEBP containing oligomers from the polymer matrix. After this initial release, the derivatized films attained an equilibrium during which no further detectable HEBP release was seen (Fig. 1).

However, when PEU matrices containing physically dispersed HEBP were incubated at $37^{\circ} \mathrm{C}$, an initial release of $26 \%$ in the first $24 \mathrm{~h}$ was observed followed by $34 \%$ release in the next 60 days. The remaining $40 \%$ of the noncovalently bound HEBP continued leaching out slowly and continuously from the films (Fig. 1).
In this case the PEU matrix behaved like a sustained release preparation, ${ }^{13-15}$ which will hypothetically prevent calcification for a limited period of time.

\section{Calcium Diffusion Studies}

The results of the calcium diffusion studies comparing underivatized and HEBP derivatized membranes are depicted in Figure 2. It can be noted from these curves that in the first $24 \mathrm{~h}$ of diffusion, the cumulative amounts of calcium diffused across the underivatized membranes was found to be $5.93 \pm 3.2 \mu \mathrm{g}$. But after $24 \mathrm{~h}$ these membranes attained equilibrium during which a steady diffusion of calcium was observed with an average diffusion of $3.742 \mu \mathrm{g} /$ day. HEBP derivatized PEU demon- 
strated $50 \%$ or less $\mathrm{Ca}^{2+}$ transport than control. The calcium diffusion decreased with increasing amounts of covalently bound HEBP. The overall presence of HEBP in the PEU appears to significantly retard the transport of calcium ions and this implies that covalent binding of HEBP to the PEU does indeed interact with ionized calcium.

\section{In Vivo Studies}

In general, explanted non-HEBP derivatized samples appeared to be yellowish and somewhat opaque. HEBP- derivatized explants retained their preimplant, translucent appearance. Although Mitrathane ${ }^{\circledR}$ (control) rat subdermal explants showed the highest amount of mineral deposition $(\mathrm{Ca}=12.6 \pm 0.9$ and $\mathrm{P}=7.9 \pm$ $0.8 \mu \mathrm{g} / \mathrm{mg}$ ), HEBP-PEU (100 $\mathrm{n} M \mathrm{HEBP} / \mathrm{mg}$ of PEU) coated over Mitrathane ${ }^{\circledR}$ showed no detectable calcium. The phosphorus detected in the HEBP derivatized unimplanted samples $(\mathrm{P}=0.6 \pm 0.2 \mu \mathrm{g} / \mathrm{mg})$ and derivatized explanted $(0.2 \pm 1.6 \mu \mathrm{g} / \mathrm{mg})$ was probably contributed by HEBP incorporated in the polymer. The variation in this phosphorus content might be due to the leaching of some unreacted phosphonate (HEBP)

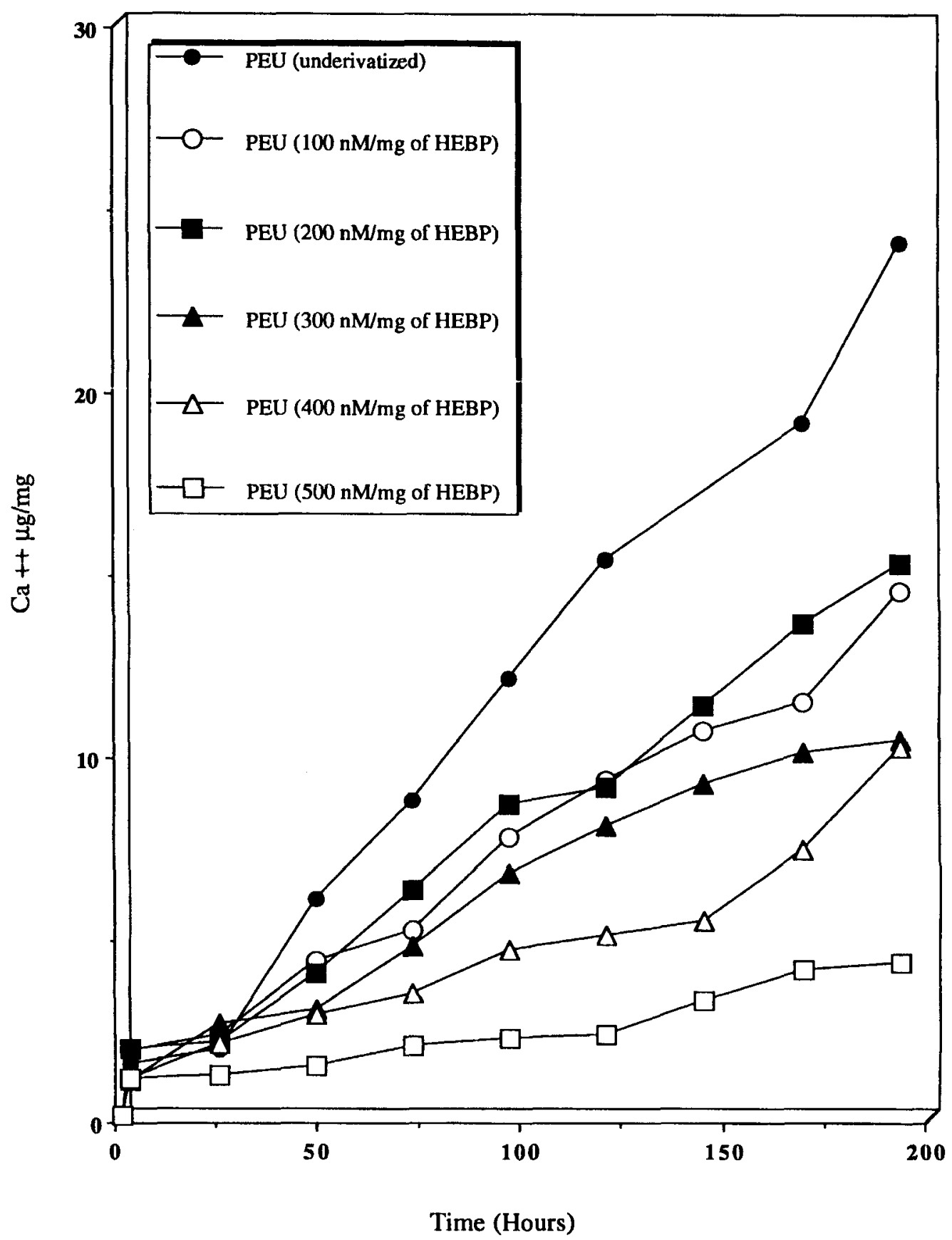

Figure 2. Comparison of cumulative calcium diffusion across the underivatized and HEBP derivatized (covalently bound) PEU membranes. 
or low molecular weight oligomers during implantation. Biomer $^{\circledR}$ demonstrated significantly less calcium phosphate deposition $(\mathrm{Ca}=1.2 \pm 0.8 \mu \mathrm{g} / \mathrm{mg}$ and $\mathrm{P}=0.6 \pm$ $0.1 \mu \mathrm{g} / \mathrm{mg}$ and $\mathrm{P}=0.6 \pm 0.1 \mu \mathrm{g} / \mathrm{mg}$ ) than Mitrathane $\left.{ }^{(}\right)$ For comparison, calcification data (Table I) on subdermal implanted glutaraldehyde cross-linked pericardium demonstrated the more severe nature of calcification of this type of material compared to polyurethane. Thus, these results have demonstrated that covalent binding of the HEBP to the polyurethane significantly inhibited PEU calcification in rat subdermal implants compared to Biomer $^{\circledR}$ and Mitrathane ${ }^{\circledR}$ controls.

\section{SEM/EDX}

Figure 3(a) and (b) shows the SEM and EDX of the explanted (60 days rat subdermal studies) Mitrathane ${ }^{\circledR}$ coated with Biomer ${ }^{\circledR}$ and HEBP-PEU (containing $100 \mathrm{n} M / \mathrm{mg}$ ). The unimplanted control polymer samples analyzed by SEM typically showed surfaces with small pits dispersed randomly, probably due to the rapid evaporation of the solvent or due to the migration of the additives during casting. ${ }^{18}$ On implantation a remarkable change was observed in the surface morphology of the samples. Surface erosion or degradation was evident in all test samples. Mitrathane ${ }^{\circledR}$ showed extensive surface cracks and fissure formation on the surface probably indicating the degradation of the polymer on the surface. Similar results have been previously reported by other researchers in the past. ${ }^{19-20}$ However, Biomer ${ }^{\circledR}$ showed a large difference in surface morphology compared to Mitrathane ${ }^{\circledR}$. The Biomer $\left.{ }^{(}\right)$surface was found to show cavities instead of cracks and fissures. Explanted HEBP derivatized PEU samples also showed more or less the same type of surface changes as noted with Biomer $^{(B)}$.

The EDX spectra of the implanted Mitrathane ${ }^{\circledR}$ and Biomer ${ }^{\circledR}$ samples demonstrated the presence of calcium and phosphorus. Figure 3(a) and (b) also shows the EDX spectrum of Mitrathane ${ }^{\circledR}$ and HEBP modified PEU. The mineral components were shown to be only on the surface of the sample and not in the bulk of the polymer. Figure 3(b) (backscattering electron image) of HEBP modified polymer also shows cracks that might be due to SEM artifact or biodegradation. Distinguishing between these possibilities was beyond the scope of the study. No calcium was detected on the surface of HEBP modified PEU explants. However, the phosphorus was found to be present on the surface of these samples, and was presumably contributed by the HEBP.

\section{ESCA}

This surface analysis technique, sensitive to depths of 30 to $100 \AA$, provides qualitative and quantitative elemental composition at an atomic level, and also in part delineates the nature of binding based on the chemical shifts. Tables II and III give the percentage contents of each element and $C_{1 s}$ peak components based on the relative area of each peak. The $\mathrm{C}_{1 \mathrm{~s}}$ high-resolution ESCA spectra of the underivatized and HEBP derivatized polyurethane (unimplanted and implanted) was deconvoluted into three main species, that is $\mathrm{C}-\mathrm{C}(285.0 \mathrm{eV}), \mathrm{C}-\mathrm{O}(286.4 \mathrm{eV})$, and $\mathrm{N}-\mathrm{COO}(289.5 \mathrm{eV})$ carbons using the assumption of $80 \%$ Gaussian and $20 \%$ Lorenzian peak shapes. The results are consistent with the nonderivatized sample being mainly composed of a poyether-type soft segment because the content of ethereal $(\mathrm{C}-\mathrm{O})$ carbon is much higher than that of urethane $(\mathrm{N}-\mathrm{COO})$ carbon. But on derivatizing with HEBP, $\mathrm{C}_{1 \mathrm{~s}}$ binding energies of the three species $(285.0,286.75$, and $289.40 \mathrm{eV})$ were all found to differ slightly from the nonderivatized PEU sample. The $\mathrm{C}_{\mathrm{ls}}$ peak components of the ether species increased and appeared as a small shoulder peak, whereas the main hydrocarbon peak decreased. The urethane $(\mathrm{N}-\mathrm{COO})$ carbon was found to be the same as the underivatized sample. On subdermal implantation of derivatized PEU in rats, the $\mathrm{C}_{1 \mathrm{~s}}$ peak components of the ether species

TABLE I. Calcium and Phosphorus Content of Rat Subdermal Implants (60 days) and Unimplanted Materials

\begin{tabular}{|c|c|c|c|c|c|c|}
\hline Polymer & & $\begin{array}{c}\mathrm{Ca}^{+2} \\
n(\mu \mathrm{g} / \mathrm{mg})\end{array}$ & $\begin{array}{l}\mathrm{SE} \\
( \pm) \\
\end{array}$ & $\begin{array}{c}\mathrm{PO}_{4}{ }^{3-} \\
(\mu \mathrm{g} / \mathrm{mg}) \\
\end{array}$ & $\begin{array}{l}\text { SE } \\
( \pm) \\
\end{array}$ & $\begin{array}{c}\text { Ratio } \\
(\mathrm{Ca} / \mathrm{P}) \\
\end{array}$ \\
\hline \multicolumn{7}{|l|}{ Implanted } \\
\hline Mitrathane ${ }^{\circledR}$ & 10 & 12.6 & 0.86 & 7.89 & 0.78 & 1.59 \\
\hline Biomer $^{\circledR}$ & 10 & 1.22 & 0.17 & 0.55 & 0.09 & 2.21 \\
\hline PEU & 10 & 0.24 & 0.04 & 0.14 & 0.07 & 1.63 \\
\hline GBP & 10 & 226.90 & 0.87 & 180.5 & 0.18 & 1.26 \\
\hline \multicolumn{7}{|l|}{ Unimplanted } \\
\hline Mitrathane $^{(\mathbb{B})}$ (C) & 4 & 0.15 & 0.00 & 0.02 & 0.00 & 7.62 \\
\hline Biomer $^{(B)}(\mathrm{C})$ & 4 & 0.15 & 0.00 & 0.03 & 0.00 & 5.70 \\
\hline PEU (C) & 4 & 0.14 & 0.00 & 0.64 & 0.00 & 0.22 \\
\hline GBP & 4 & 0.33 & 0.00 & 0.21 & 0.00 & 1.60 \\
\hline
\end{tabular}

C, control sample; $100=100$ nм of EHDP covalently bound; GBP, glutaraldehyde pretreated bovine pericardium; $\boldsymbol{n}$, number of samples used for analyses. 


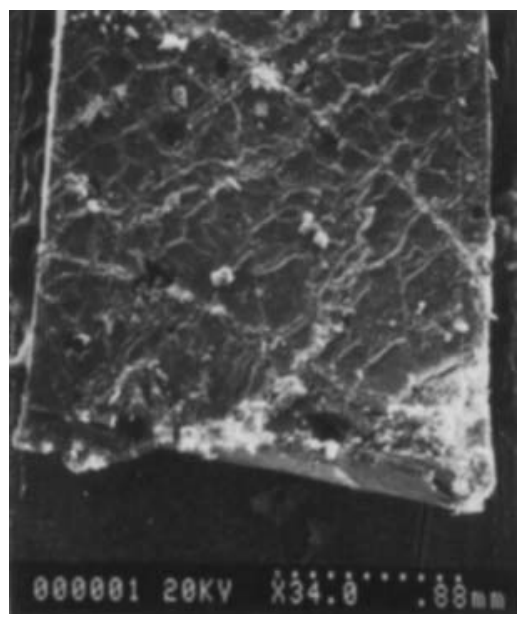

Sconning Electron Microscopic Image
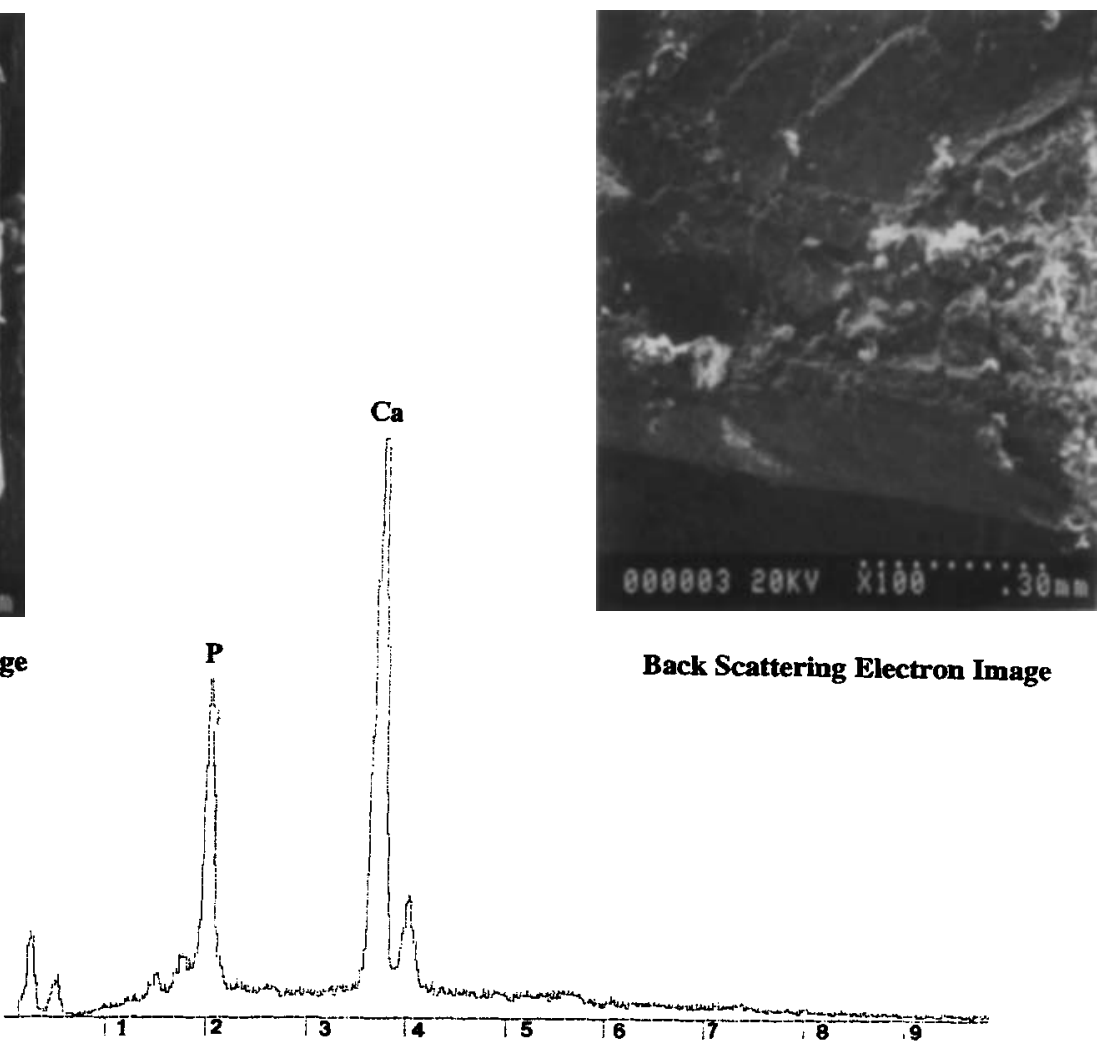

Back Scattering Electron Image

Figure 3(a). Scanning electron microscopy (SEM)/energy dispersive $x$-ray (EDX) of Mitrathane ${ }^{\circledR}$ implanted sample in rat for 60 days.

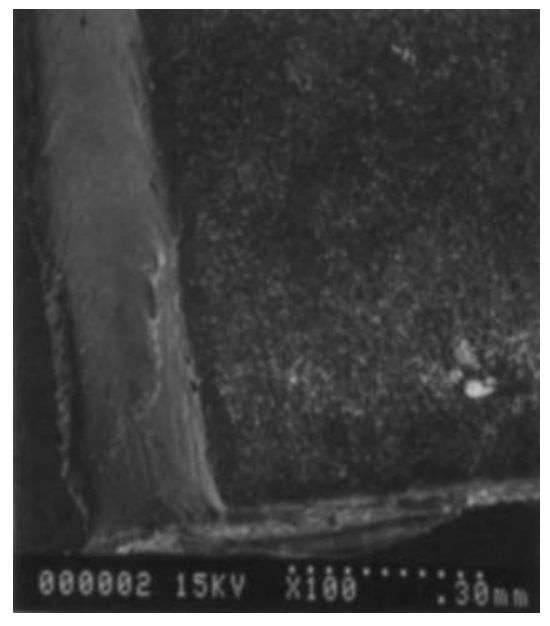

Scanning Electron Microscopic Image

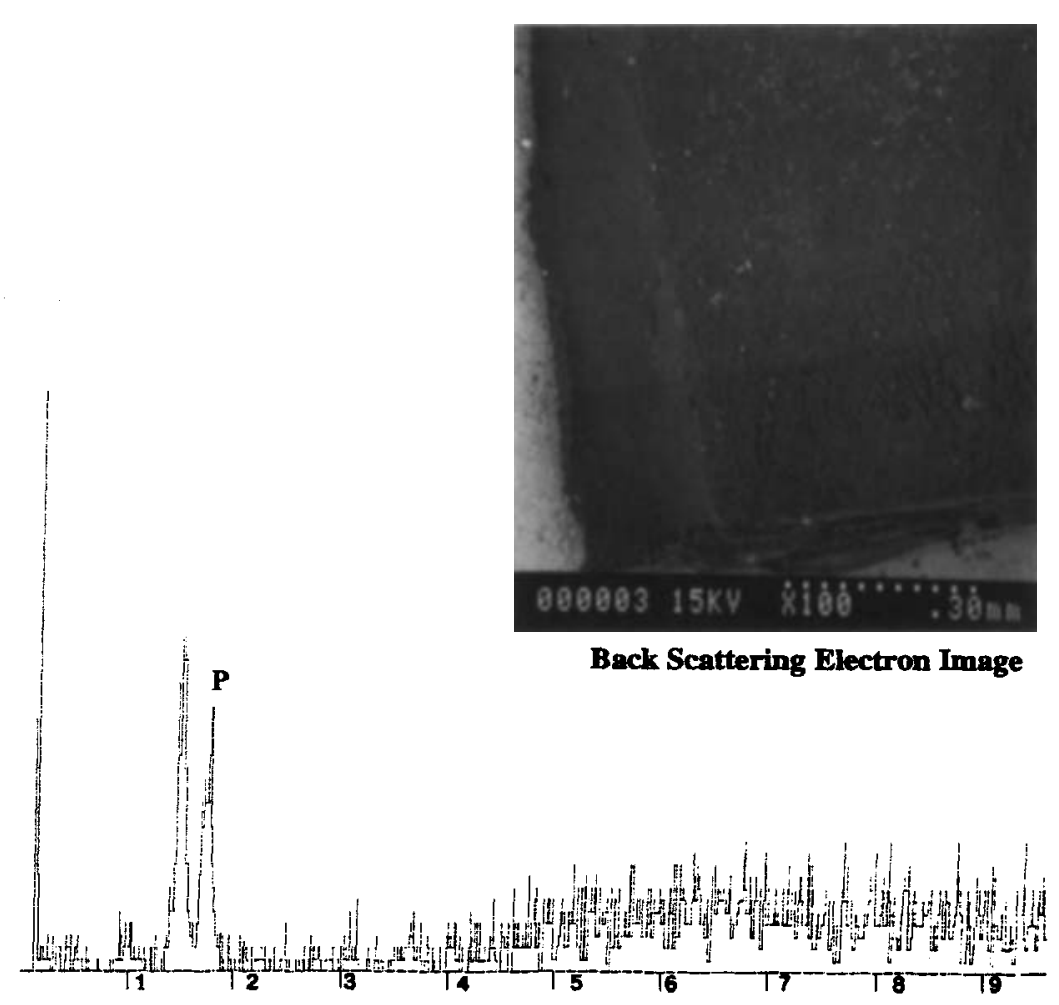

Figure 3(b). Scanning electron microscopy (SEM)/energy dispersive $x$-ray (EDX) of PEU (100 $\mathrm{nM} / \mathrm{mg}$ HEBP) implanted sample in rat for 60 days. 
TABLE II. ESCA of Various Elements Present on Surface of Phosphonated PEU

\begin{tabular}{llllll}
\hline & \multicolumn{5}{c}{ Elements Present (\%) } \\
\cline { 2 - 6 } \multicolumn{1}{c}{ Polymer Code } & $\mathrm{C}_{1 \mathrm{~s}}$ & $\mathrm{O}_{1 \mathrm{~s}}$ & $\mathrm{~N}_{1 \mathrm{~s}}$ & $\mathrm{Si}_{2 \mathrm{p}}$ & $\mathrm{P}_{2 \mathrm{p}}$ \\
\hline PEU (underivatized) & 79.0 & 19.3 & 1.7 & $\mathrm{ND}$ & $\mathrm{ND}$ \\
PEU (derivatized) & 76.1 & 21.6 & 1.9 & 1.27 & $\mathrm{ND}$ \\
PEU (implanted derivatized) & 72.6 & 23.5 & 3.3 & 0.7 & $\mathrm{ND}$ \\
\hline
\end{tabular}

ND, Not detected.

decreased and that of the main hydrocarbon and urethane $(\mathrm{N}-\mathrm{COO})$ carbon peaks uncreased and these results may be explained by phase reversal.

\section{FTIR-AIR}

Figure 4(a), (b), and (c) shows the FTIR-ATR spectra of underivatized, HEBP derivatized unimplanted, and HEBP derivatized explanted polyurethane samples containing $100 \mathrm{nM}$ of covalently bound HEBP. The characteristic peaks of each of the major transmittance bands is described in Table IV. Comparisons of unimplanted underivatized and derivatized PEU show remarkable changes in peak positions and intensities of prominent peaks such as the amide I and II, carbonyls and ether peaks. The amide I peak became broader and shifted $15 \mathrm{~cm}^{-1}$ downfield and the intensity of the bonded carbonyl decreased and that of the ether peak increased. The intensity of some of the peaks in the fingerprint region was found to increase on derivatization. Overall the intensity of the peaks corresponding to the soft segment were found to be more prominent than the hard segment.

On subdermal implantation (rats, 60 days), the spectra when compared to derivatized unimplanted controls showed a significant change in the peak pattern and position corresponding to hard and soft segments. The intensity of the hard segment peaks was found to have increased as compared to HEBP derivatized unimplanted controls. Two new small peaks at 1174 and $771 \mathrm{~cm}^{-1}$ related to oxidative degradation ${ }^{21}$ were detected in the derivatized implanted samples identified as ester functionalities. Biomer ${ }^{\circledR}$ and Mitrathane ${ }^{\circledR}$ (unimplanted and explanted samples) showed a remarkable change in the peak positions and intensities corresponding to hard and soft segments. Before implantation, the derivatized unimplanted control sample showed the surface to be rich in soft segment components, and after implanting demonstrated a relative hard segment enrichment. The implanted Mitrathane $\left.{ }^{(}\right)$samples showed relatively more prominent changes demonstrating in the peak intensities (compared to unimplanted) than did the implanted Biomer ${ }^{\circledR}$ samples.

\section{Water Absorption Studies}

The water absorption capacity of the underivatized and derivatized samples with different compositions of covalently bound HEBP showed increasing water absorption with increases in the level of incorporation of bisphosphonate. The increased hydrophilicity of the derivatized samples could be attributed to the incorporation of HEBP in the polymer matrix. This increase in hydrophilicity could hypothetically contribute enhancement of the nonthrombogenicity of the polymer. ${ }^{22}$

GPC. Table V shows the molecular weight data for the various polymers samples analyzed before and after implantation. In the case of the HEBP-derivatized unimplanted PEU, the $M_{\mathrm{n}}$ decreased by 8.1 and $M_{\mathrm{w}}$ by $0.65 \%$, respectively, as compared to underivatized PEU. On implanting, $M_{\mathrm{n}}$ decreased by $9.69 \%$ and $M_{\mathrm{w}} 21.18 \%$ compared to underivatized PEU. The dispersity (MWD) was found to have increased on derivatization and implantation. The implanted Biomer ${ }^{\circledR}$ demonstrated a decrease of $15 \%$ from $M_{\mathrm{n}}, 35 \%$ for $M_{\mathrm{W}}$, and $24 \%$ for MWD compared to unimplanted. Similarly, implanted Mitrathane ${ }^{\circledR}$ showed a decrease of $10.5 \%$ for $M_{\mathrm{w}}$ and $12.5 \%$ for MWD, respectively. However, the $M_{\mathrm{n}}$ of the implanted Mitrathane ${ }^{\circledR}$ was found to have increased by $2.5 \%$.

\section{DISCUSSION}

Our present investigation was focused on the anticalcification efficacy of HEBP covalently bound to polyurethane. The principal findings of this study were:

1. Covalent binding of HEBP to the proprietary synthesized polyurethane was stable and efficient.

2. ESCA and FTIR-ATR studies demonstrated the incorporated HEBP to be associated with the soft segment.

3. Diffusion of calcium solution through the derivatized polymers decreased with increasing levels of covalent bound HEBP.

4. There was an anticalcification effect of covalently bound HEBP when compared to Biomer $^{\circledR}$ and Mitrathane ${ }^{\circledR}$ as demonstrated by calcium analyses of the rat subdermal explants.

TABLE III. ESCA $C_{1 s}$ Peak Components

\begin{tabular}{lcccc}
\multicolumn{1}{c}{ Polymer Code } & $\mathrm{C}-\mathrm{C}(\%)$ & $\mathrm{C}-\mathrm{O}(\%)$ & $\mathrm{N}-\mathrm{COO}(\%)$ & $\mathrm{C}-\mathrm{O} / \mathrm{N}-\mathrm{COO}(\%)$ \\
\hline PEU (underivatized) & 59.4 & 38.6 & 1.7 & 22.70 \\
PEU (derivatized) & 58.9 & 39.4 & 1.7 & 23.17 \\
PEU (implanted derivatized) & 61.0 & 34.2 & 4.9 & 6.97 \\
\hline
\end{tabular}




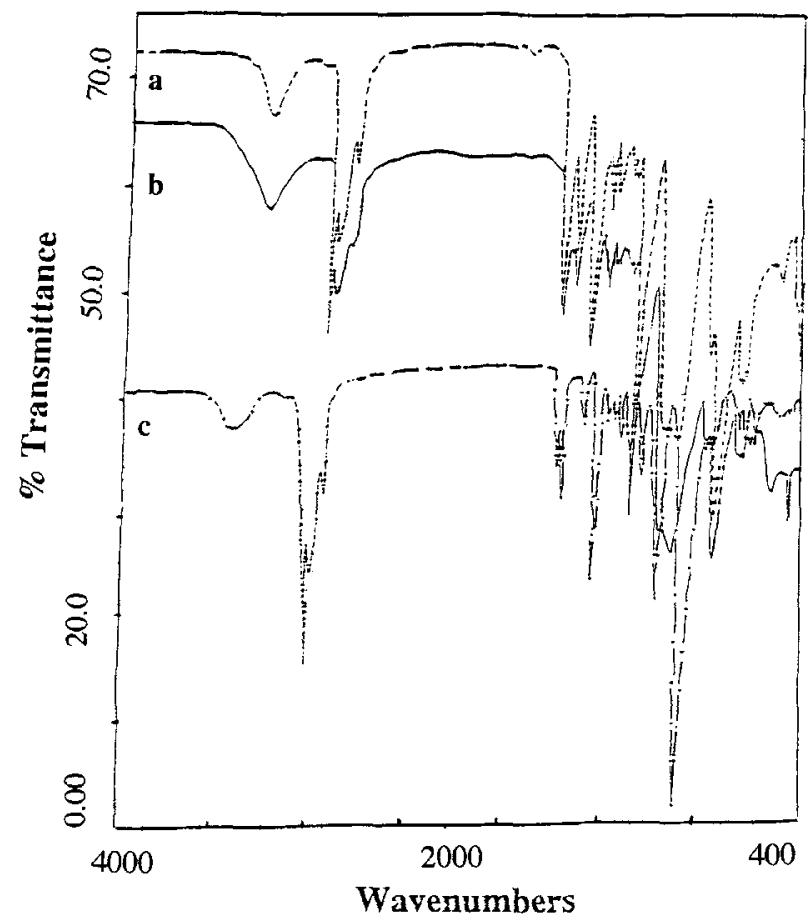

Figure 4. FTIR-ATR spectra of (--), (-) derivatized unimplanted PEU, and $(. .-)$ in rat for 60 days.

Calcification of bioprosthetic or synthetic heart valves is the most frequent cause of clinical failure. Prevention of this pathophysiological event is possible by either altering the implant through pretreatment procedures or through the therapeutic administration of an anticalcification agent. The former technique may deleteriously affect the physical and chemical properties of the material and biological properties of the prostheses, whereas the later may have untoward side effects on normal metabolism and bone physiology. Most of the work published in the literature concerned with inhibition of implant calcification has been on the modification of porcine aortic valve bioprostheses. Recently, the use of commercially available medical grade PEUs, such as Biomer ${ }^{\circledR}$, Mitrathane ${ }^{\circledR}$, and Pellethane ${ }^{\circledR}$ have been evaluated for various cardiovascular applications such as artificial heart devices and heart valve prostheses. However, these polymers are also reported to calcify either in vitro or in vivo or both. ${ }^{5-9}$ Although the pathogenesis of PEU calcification is different from that reported for bioprosthetic heart valves, the principal mineral phase component of calcification is most likely hydroxyapatite in both types of mineralization. Calcification results in loss of important physical, chemical, and biological properties of the implant eventually leading to its failure.

Previous studies from our group have demonstrated that local site-specific therapy with controlled release HEBP-polymers and HEBP-glutaraldehyde pretreated bioprosthetic heart valve (BPHV) prevented calcification in rat subdermal implants with no side effects. ${ }^{10-14,23-25}$ However, this method is limited by the duration of sus- tained HEBP release. The exact mechanism of inhibition of physiological and pathological calcification by HEBP is still incompletely understood. Some believe HEBP prevents calcification by steric chemoabsorption to calcium phosphate nuclei, leading to the inhibition of further crystal growth, whereas others have reported HEBP to behave as a detergent, by decreasing the number of available nucleation sites for hydroxyapatite. ${ }^{4}$ Others have suggested that HEBP may act by inhibiting alkaline phosphatase. $^{4}$

HEBP-Binding Stability:In Vitro Release Study. The results of in vitro studies performed for more than 1 year demonstrated that a majority of the initial covalently incorporated HEBP remained in the polymer. If the HEBP had not been covalently bound (versus physically dispersed) to PEU, it would be expected to have continuously diffused from the polymer until the physically dispersed HEBP was exhausted through diffusion and thus, calcification would have resumed. This study further removes doubts that the reacted bisphosphonate could have simply become entrapped in the polymer matrix by various physical forces such as hydrogen bonding, Van Der Walls force of attraction. However, gradual HEBP release would have been expected had there not been permanent binding to the polymer chain.

\section{Calcium Diffusion Studies}

Based on our calcium diffusion studies, the presence of HEBP in the PEU greatly reduces the immediate calcium influx. Therefore, covalently bound HEBP could hypothetically retard the kinetics of initial crystalline calcium phosphate formation by inhibiting calcium permeation. This could be explained as follows: It has been reported that HEBP forms polynuclear aggregates with calcium ions under physiological conditions. ${ }^{26}$ Although the exact mechanism of the calcium-HEBP aggregation is still not clearly understood it is suggested to take place through the aliphatic alcoholic and the neighboring two phosphonic acid groups and thus hinders the attraction of phosphate ion for further crystallization of calcium phosphates. The PEU-HEBP membranes in our studies could be binding calcium ions and thereby blocking nucleation sites thus preventing the diffusion of calcium ion either through charge repulsion or by blocking theoretical molecular pores.

\section{In Vivo Studies}

The results from the in vivo studies have clearly indicated that covalent HEBP incorporation was effective in preventing calcification in rat subdermal implants as compared to controls (Biomer ${ }^{\circledR}$ and Mitrathane ${ }^{\circledR}$ ). ESCA and FTIR-ATR results did not detect HEBP on the surface of the explanted derivatized polymer, despite the significant anticalcification activity of the HEBP-derivatized 
TABLE IV. Principal ATR-FTIR Peak Assignment for Polyurethane

\begin{tabular}{|c|c|c|}
\hline $\begin{array}{l}\text { Wave Number } \\
\qquad\left(\mathrm{cm}^{-1}\right)\end{array}$ & Relative Intensity & Peak Assignment \\
\hline 3420 & W, Sh & $\nu(\mathrm{N}-\mathrm{H})$ free $\mathrm{NH}$ \\
\hline 3325 & $\mathrm{~S}$ & $\nu(\mathrm{N}-\mathrm{H})$ bonded $\mathrm{NH}$ \\
\hline 2937 & $S$ & $\nu\left(\mathrm{CH}_{2}\right)$ in ET only \\
\hline 2852 & $S$ & $\nu\left(\mathrm{CH}_{2}\right)$ in ET only \\
\hline 2795 & M & $\nu\left(\mathrm{CH}_{2}\right)$ in ET only \\
\hline 1729 & VS & $\nu(\mathrm{C}=\mathrm{O})$ free $\mathrm{C}=\mathrm{O}$ \\
\hline 1595 & $\mathrm{~S}$ & $\nu(\mathrm{C}=\mathrm{C})$ in benzene ring \\
\hline 1530 & VS & $\delta(\mathrm{NH})+n(\mathrm{C}-\mathrm{N})$ \\
\hline 1413 & $S$ & $\nu(\mathrm{C}-\mathrm{C})$ in benzene ring \\
\hline 1366 & M & $\omega\left(\mathrm{CH}_{2}\right)$ \\
\hline 1309 & $\mathrm{~S}$ & $\delta(\mathrm{NH})+n(\mathrm{C}-\mathrm{N}), \mathrm{b}(\mathrm{C}-\mathrm{H})$ \\
\hline 1251 & $\mathrm{~S}, \mathrm{Sh}$ & $\left.\mathrm{CH}_{2}\right), n(\mathrm{C}-\mathrm{O}-\mathrm{C})$ in $-\underset{\mathrm{O}}{\mathrm{C}}-\mathrm{O}-\mathrm{C}-$ \\
\hline 1220 & $S$ & $\delta(\mathrm{NH})+n(\mathrm{C}-\mathrm{N})$ \\
\hline 1102 & VS & $\begin{array}{l}\nu(\mathrm{C}-\mathrm{O}-\mathrm{C}) \text { or } n(\mathrm{Si}-\mathrm{O}-\mathrm{Si}) \text { aliphatic } \\
\text { ether }\end{array}$ \\
\hline 1080 & $S$ & $\nu(\mathrm{C}-\mathrm{O}-\mathrm{C})$ in hard segment $(\mathrm{C}-\mathrm{O}-\mathrm{C})$ \\
\hline 1017 & W & $\beta(\mathrm{C}-\mathrm{H})$ in benzene ring \\
\hline 817 & W & $\gamma(\mathrm{C}-\mathrm{H})$ in benzene ring \\
\hline 771 & W & $\gamma(-\underset{\|}{\mathrm{C}}-\mathrm{O}-)$ \\
\hline
\end{tabular}

$\nu$, stretching; $\delta$, bending; $\beta$, in plane bending; $\gamma$ out of plane bending; $\omega$, wagging; $W$, weak; Sh, shoulder; S, sharp; M, medium; VS, very sharp.

polymer and the continued presence of HEBP based on the radioactive release results. This might be due to the phase change taking place on implantation, resulting in a subsurface location of the covalently bound drug or alternatively, the surface concentration of HEBP may be below the detection limits of our instrument. The detection of phosphorus on the surface of the HEBP-PEU implanted sample by SEM-EDX with no sign of calcium presence either on the surface or bulk of the polymer may indicate that the incorporated HEBP migrated onto the surface on implantation. Cracks seen on the surface in Figure 3(b) (backscattering electron image) might be due to SEM artifact. Further investigation of the nature of these surface images in the HEBP modified polymers will be done in the future. As seen in results of the explanted Biomer ${ }^{\circledR}$ and Mitrathane ${ }^{\circledR}$ samples, increased calcium and phosphorus was detected and confirmed by elemental analysis. Furthermore, the nucleation of calcification as seen from the SEM studies identified to be a surface phenomenon with no mineralization detected in the bulk of the polymer.

\section{ESCA}

Although no direct evidence for the presence of HEBP on the subsurface of the modified polymer could be obtained by ESCA, indirect evidence for its incorporation as a soft segment was demonstrated by the changes in the peak pattern, position, and intensity of the spectrum. The $\mathrm{C}_{1 \mathrm{~s}}$ binding energies of three possible carbon domains $(285.0,286.75$, and $289.40 \mathrm{eV})$ of derivatized unimplanted PEU were found to be slightly inconsistent as compared to the nonderivatized PEU sample. This might be because of the incorporation of the bulkier HEBP group into the polymer chain causing differences in the electronic distribution around $\mathrm{C}-\mathrm{O}$ species resulting from a shifting of the peak to a higher binding energy. The increase in oxygen atomic composition as shown in Table II and the ethereal $(\mathrm{C}-\mathrm{O})$ carbon as shown in Table III, probably indicate that the incorporated HEBP forms an ether type of linkage and is distributed in the soft segment of the polymer matrix. This is confirmed by the increase in the ratio of the percent $\mathrm{C}-\mathrm{O} / \mathrm{N}-\mathrm{COO}$. The implanted sample showed carbamate rich $(\mathrm{N}-\mathrm{COO})$ hard segment species suggesting a loss of ether linkages either due to degradation or due to the phase change of segments following an exposure to the pepsin solution used to remove the surface-adhered proteins or possibly during the storage of the samples following explants. ${ }^{27-29}$ The decrease in the ratio of percent $\mathrm{C}-\mathrm{O} / \mathrm{N}-\mathrm{COO}$ further confirms the surface to be rich in hard segment of phosphorus peaks in all the derivatized (unimplanted and implanted) samples 
indicates (as discussed above) that either the phosphonate groups might be buried in the bulk, or more likely that the amount of phosphonate incorporated into the polymer was beneath the detection limits.

\section{FTIR-ATR}

FTIR-ATR spectroscopic studies revealed no phosphorus peaks in the expected region, around $1100 \mathrm{~cm}^{-1}$, and this may be due to the fact that some of the peaks corresponding to the polymer also fall in the same region. However, comparing relative intensities of peaks in the region where the phosphonate peak might be expected to appear, a prominent change in peak position and intensity was noted. On derivatization, the $1100 \mathrm{~cm}^{-1}$ peak shifted in the range of 40 to $50 \mathrm{~cm}^{-1}$ upfield. This region usually identified as a polyether peak, indicates that the covalent binding the HEBP through the proprietary reaction mechanism leads to an ether type of linkage and thus the HEBP is dispersed in the soft segment of the polymer matrix. Because of the incorporation of HEBP in the polymer chain as a soft segment, a noticeable change in hydrogen bonding is observed. Spectra of HEBP derivatized PEU showed the NH band, which is strongly hydrogen bonded in nonderivatized PEU, to have a broad shoulder peak, a decrease in band intensity, and an upfield shift of $55 \mathrm{~cm}^{-1}$. This can be explained by the possible rupture of hydrogen bonding between the $\mathrm{NH}$ group arising from the hard segment and the ethereal or carbonyl oxygen group, probably resulting in hydrogen bonding between the phosphonate and ether linkage because of the electronegative nature of HEBP. Such an effect implies that incorporation of HEBP in the polymer chain resulted in a plasticization-like effect in the bulk of the polymer causing a phase separation.

In nonderivatized PEU, the NH-II amide band in the region of $3325 \mathrm{~cm}^{-1}$ appears to be completely hydrogen bonded, which is probably due to the hydrogen bond

\begin{tabular}{|c|c|c|c|}
\hline Polymer Code & $M_{\mathrm{n}}$ & $M_{\mathrm{w}}$ & MWD \\
\hline \multicolumn{4}{|l|}{ Biomer ${ }^{(\mathbb{B}}$} \\
\hline Unimplanted & $1.27 * 10^{6}$ & $6.67 * 10^{6}$ & 5.24 \\
\hline Explanted & $1.08 * 10^{6}$ & $4.30 * 10^{6}$ & 3.96 \\
\hline \multicolumn{4}{|l|}{ Mitrathane ${ }^{\circledR}$} \\
\hline Unimplanted & $6.07 * 10^{5}$ & $2.39 * 10^{6}$ & 3.93 \\
\hline Explanted & $6.22 * 10^{5}$ & $2.14 * 10^{6}$ & 3.44 \\
\hline \multicolumn{4}{|l|}{ PEU } \\
\hline Unimplanted & $9.74 * 10^{5}$ & $2.65 * 10^{6}$ & 2.72 \\
\hline Derivatized & $7.91 * 10^{5}$ & $2.42 * 10^{6}$ & 3.03 \\
\hline Explanted & $6.72 * 10^{5}$ & $2.65 * 10^{6}$ & 3.53 \\
\hline
\end{tabular}

$M_{n}$, Number average molecular weight; $M_{w}$, weight average molecular weight; MWD, molecular weight dispersion; PEU contain $100 \mathrm{n} M$ of covalently bound HEBP. formation between the NH group from the hard segment and ether-oxygen or the carbonyl-oxygen from the soft segment or both. This suggests that there is complete phase mixing in this newly synthesized medical grade polyurethane. On covalent binding of HEBP through the proprietary reaction (derivatized), the NH-II amide band appeared with a broad shoulder peak, decreased in band intensity, and shifted upfield by 30 to $55 \mathrm{~cm}^{-1}$ as compared to the underivatized PEU. This indicates that the hydrogen bonding must have been disturbed due to the incorporation of bulkier HEBP resulting in a phase change confirmed by the increase in carbonyl hydrogen bonding peak. The increase in the ratio of the peak intensities of the bands at $1102 \mathrm{~cm}^{-1}(\mathrm{C}-\mathrm{O}-\mathrm{C})$, representing the soft segment concentration, and the band at $1080 \mathrm{~cm}^{-1}$ $(\mathrm{CO}-\mathrm{O}-\mathrm{C})$ representing the hard segment concentration, further confirms that the incorporated HEBP behaves as a soft segment in the polymer matrix.

On explanting (rat subdermal, 60 days) the derivatized PEU containing $100 \mathrm{n} M$ of covalently bound HEBP showed a considerable change in peak intensities for the peaks representing the soft segments $\left(966,1110,1367,2796,2856\right.$, and $\left.2939 \mathrm{~cm}^{-1}\right)$ and hard segments $(771,1066,1221,1310,1412,1539,1639$, and $3320 \mathrm{~cm}^{-1}$ ). The hard segment peaks were found to be more pronounced in the explanted sample with respect to those representative of the soft segment. These results suggest that either the hard segment moving to the surface, or a loss of soft segment on the surface (perhaps through phase reversal) are the most likely explanations for the spectral changes observed. The latter possibility is supported by ESCA studies. Besides the increase in hard segment concentration on the surface, an increase in hydrogen bonding was also noted. This might be due to the formation of more hydrogen bonding functionalities on implanting. Two new small peaks at 1174 and $771 \mathrm{~cm}^{-1}$ were detected in the derivatized implanted samples suggesting an increase in ester functionalities that might be due to the oxidation of the ether linkages indicating that HEBP may not retard surface oxidation. Thus, these results could indicate that some surface changes occur on implantation leading to the surface becoming relatively enriched in hard segment concentration.

\section{Water Absorption Studies}

The derivatized polymers, which were found to be more hydrophilic than the underivatized polymers, may handle water differently due to the incorporation of HEBP as part of the soft segment in the polymer chain. The increased hydrophilicity of the derivatized polymer might also contribute to the thromboresistance. ${ }^{22}$ In a previous study by Golomb, ${ }^{30}$ it was reported that the porosity and water absorption capacity of PEU may increase the potential for calcification in rat subdermal implants. How- 
ever, the present HEBP derivatized materials, which were increasingly hydrophilic in nature with increased amounts of incorporated HEBP, had no calcification following rat subdermal implantation.

\section{GPC}

The HEBP modified PEUs showed negligible changes in bulk properties. When tested for solubility in various polar solvents, the derivatized PEUs dissolved relatively more slowly than the control samples because of the slight increase in molecular weight as seen from GPC data. The slight increase in $M_{\mathrm{n}}$ and a large increase in $M_{\mathrm{w}}$ indicates that the polymer molecule may have undergone a coupling reaction between large and small polymer chains on covalent binding of HEBP. The increase in dispersity could also be attributed in part to formation of some low molecular weight oligomers or unreacted HEBP during the binding reaction as seen from the release kinetics study.

\section{SUMMARY AND CONCLUSIONS}

A series of proprietary medical grade PEU was successfully derivatized by covalent binding of 100 to $500 \mathrm{nM} / \mathrm{mg}$ of HEBP through a proprietary reaction mechanism. Based on the release kinetics studies, it can be concluded that the covalent binding of HEBP through the proprietary reaction mechanism is efficient, stable, and permanent. The bound HEBP is incorporated in the soft segment as demonstrated by ESCA and FTIRATR studies. The molecular weight of the modified polymer sample increased slightly, but the dispersity increased appreciably. This might be due to the binding of HEBP to the chains of various molecular weights within the polymer matrix. The water absorption of the modified PEU increased with increasing incorporation of bound HEBP. In vivo implanted samples showed a slight change in surface and bulk properties. The surface of the implanted sample becomes richer in hard segment concentrations. In vivo implantation resulted in a slight decrease in molecular weight, which might be due to the oxidation of the ether linkages or diffusion of low molecular weight. HEBP containing oligomers. Furthermore, the results of rat subdermal implants demonstrated that covalently bound HEBP was an effective means for inhibiting the calcification of polyurethanes. Thus, HEBP containing PEU is a promising candidate for preparing cardiovascular implants that will resist calcification.

This research was supported by a research contract from CarboMedics Inc., Austin, TX. We also thank Ms. Emily Graves and Mr. Tom Underwood for assisting with these experiments.

\section{REFERENCES}

1. Lelah, M. D.; Cooper, S. L. Polyurethanes in medicine. Boca Raton, FL: CRC Press; 1986.

2. Szycher, M. High performance biomaterials: a comprehensive guide to medical and pharmaceutical applications. Lancaster, PA: Technomic Publishing Co; 1991:37-71.

3. Szycher, M. Biocompatable polymers, metals, and composites. Lancaster, PA: Technomic Publishing Co; 1983:103164.

4. Levy, R. J.; Schoen, F. J.; Golomb, G. Bioprosthetic heart valve calcification: clinical features, pathobiology and prospective for prevention. Biocompatibility 2:147-187; 1986.

5. Golomb, G.; Wagner, D. Development of a new in vitro model for studying implantable polyurethane calcification. Biomaterials 12:397-405; 1991.

6. Hilbert, S. L.; Ferrans, V.J.; Tomita, Y.; Eidbo, E. E.; Jones, M. Evaluation of explanted polyurethane trileaflet cardiac valve prostheses. J. Thorac. Cardiovasc. Surg. 94:419-429; 1987.

7. Whalem, R. L.; Snow, J. L.; Harasaki, H.; Nose, Y. Mechanical strain and calcification in blood pumps. Trans. Am. Artif. Intern. Organs 24:487-491; 1980.

8. Harasaki, H.; Moritz, A.; Uchida, N.; et al. Initiation and growth of calcification in polyurethane coated blood pumps. Trans. Am. Soc. Artif. Intern. Organs 33:643-649; 1987.

9. Wisman, C. B.; Pierce, W. S.; Donachy, J. H.; Pae, W. E.; Myers, J. L.; Prophet, G. A. A polyurethane trileaflet cardiac valve prosthesis: in vitro and in vivo studies. Trans. Am. Soc. Artif. Intern. Organs 28:164-168; 1982.

10. Levy, R.J.; Golomb. G.; Wolfrum, J.; Lund, S. A.; Schoen, F. J.; Langer, R. Local controlled release of diphosphonates from ethylene vinyl acetate matrices prevnts bioprosthetic heart valve calcification. Trans. Am. Soc. Artif. Intern. Organs 31:459-463; 1985,

11. Johnston, T.P.; Golomb. G.; Levy, R. J. Local controlled release of 1-hydroxyethylidene diphosphonate using silicone matrices: effects of sterilization on in vitro release and in vivo efficacy. Trans. Am. Soc. Artif. Intern. Organs 34:835-838; 1988.

12. Golomb. G.; Dixon, M.; Smith, M.S.; Schoen, F. J.; Levy, R.J. Controlled-release drug delivery of diphosphonate to inhibit bioprosthetic heart valve calcification: release rate modulation with silicone matrices via drug solubility and membrane coating. J Pharmacol. Sci. 76:271-276; 1987.

13. Golomb. G.; Wagner, D. Characterization and anticalcification effects of implantable polyurethane matrices containing amorphous dispersion of bisphosphonic acid. Clin. Mater. $8: 33-42 ; 1991$.

14. Johnston, T. P.; Boyd, J. A.; Ciesliga, B. L.; et al. Controlled release of hydroxyethanebisphosphonate from polyurethane reserviors to inhibit calcification of bovine pericardium used in bioprosthetic heart valves. Int. J. Pharmacol. 59:95-104; 1990.

15. Golomb, G.; Langer, R.; Schoen, F. J.; Smith, S. M.; Choi, Y.; Levy, R. J. Controlled release of diphosphonate to inhibit bioprosthetic heart valve calcification: dose-response and mechanistic studies. J. Controlled Release 4:181-194; 1986.

16. Schoen, F. J.; Tsao, J. W.; Levy, R. J. Calcification of bovine pericardium used in cardiac valve bioprosthesis: implication for the mechanism of bioprosthetic tissue mineralization. Am. J. Pathol. 123:134-144; 1986.

17. Chen, P.S.; Toribira, T. Y.; Warner, H. Microdetermination of phosphorous. Anal. Chem. 28:1756-1758; 1956. 
18. Bruck, S. D. Properties of biomaterials in the physiological environment. Boca Raton, FL: CRC Press; 1980.

19. Zhao, Q. H.; Anderson, J. M.; Hiltner, A. Theoretical analysis on cell size distribution and kinetics of foreign body giant cell size formation in vivo on polyurethane elastomers. J. Biomed. Res. 26:1019-1038; 1992.

20. Zhao, Q.H.; Mcnally, A. K.; Rubin, K. R; et al. Human plasma $\alpha_{2}$-macroglobulin promotes in vitro oxidative stress cracking of pellethane 2363-80A: In vivo and in vitro correlations. J. Biomed. Mater. Res. 27:379-389; 1993.

21. Wu, Y.; Sellitti, C.; Anderson, J. M.; Hiltner, A.; Lodeon, G. A.; Payet, C. R. J. Appl. Polym. Sci. 16:201-208; 1992.

22. Desai, N.P.; Hubbell, J. A. Solution to incorporate polyethylene oxide and other water soluble polymers into surface of polymeric biomaterials. Biomaterials 12:143-152; 1991.

23. Webb, C. L.; Schoen, F. J.; Levy, R.J. Covalent binding of aminopropane hydroxydiphosphonate to glutaraldehyde residue in pericardial bioprosthetic tissue: stability and calcification inhibition studies. Expt. Molecular Pathol. 50:291-302; 1989.

24. Webb, C. L.; Benedict, J. J.; Schoen, F. J.; Linden, B. A.; Levy, R.J. Inhibition of bioprosthetic heart valve with aminodiphosphonate covalently bound to residual groups. Ann. Thorac. Surg. 46:309-316; 1988.
25. Levy, R. J.; Hawley, M. A.; Schoen, F. J.; Lund, S. A.; Liu, P. U. Inhibition by diphosphonate compounds of calcification of porcine bioprosthetic heart valve by local controlled release diphosphonate. Science 228:190-192; 1985.

26. Francis, M.D. Calcified Tissue Res. 3:36-39; 1969.

27. Grasel, T. G.; Lee, D. C.; Okkema, A.Z.; Slowinski, T.J.; Cooper, S. L. Extraction of polyurethane block copolymers: effects on bulk and surface properties and biocompatibility. Biomaterials 10:23-32; 1989.

28. Ratner, B.D. Treatise on clean surface technology, Vol. 2, Mittal, K. L., Ed., New York: Plenum Publishing Corp.; 1987.

29. Ratner, B. D. Physicochemical aspects of polymer surfaces. Vol. 2, Mittal, K. L., Ed., New York: Plenum Publishing Corp., 1983.

30. Golomb, G. Calcification of polyurethanes-based biomaterials implanted subcutaneously in rats: role of porosity and fluid absorption in the mechanism of mineralization. J. Mater. Sci. Mater. Med. 3:272-281; 1992.

Received July 12, 1993 Accepted November 17, 1993 